\title{
malang Ceramic Craft Center Dengan Pendekatan Arsitektur REgionalisme Di Kota Malang
}

\author{
Afidah Silmi, Suparno, Dyah S. Pradnya P. \\ Program Studi Arsitektur \\ Jurusan Arsitektur Fakultas Teknik \\ Universitas Sebelas Maret Surakarta \\ Email : afidahsilmi92@gmail.com
}

\begin{abstract}
Designing Malang Ceramic Craft Center in Malang City motivated by the potential of ceramics craft, which currently increasing, support the efforts of the Malang City government to raising tourism, as well as Malang as one of the producers of ceramics craft that do not have an adequate infrastructure of tourism education and marketing. The purpose of this architectural planning is to provide a place for tourist, so that they can fulfill the tourism needs and to give the information about ceramics craft, as well as to help raising the income of Malang City through the marketing of ceramics craft. The issue of the design are: how to build Malang Ceramic Craft Center with the application of Regionalism Architecture for the building planning. The approach used in determining the design is by using the concept of Regionalism Architecture which is applied in form and fasade building, the pattern of mass arrangement, as well as the material and structure building. The result obtained is the design of an education tourism facilities that is Malang Ceramic Craft Center with Regionalism Architecture approach, which can visible in the use of Javanese traditional rooftop, joglo, the use of building color as an adjustment with buildings around, the mass form in accordance with the mass form of Javanese building, the application of ceramics craft ornament on building, the use of sculpture in accordance with the material object symbol and the use of local material on building.
\end{abstract}

Keywords: Ceramic Craft, Fasade Building, Local Culture. Regionalism Architecture, Tourism Facility.

\section{PENDAHULUAN}

Indonesia merupakan negara yang kaya akan budaya. Didukung oleh kreativitas dari bangsa Indonesia sendiri, budayabudaya tersebut menghasilkan berbagai kerajinan khas Indonesia, salah satunya kerajinan keramik.

Saat ini, keberadaan kerajinan keramik di Indonesia sudah mulai banyak diminati oleh para wisatawan. Hal ini dapat dilihat dari meningkatnya permintaan akan kerajinan keramik. Berdasarkan data yang diperoleh dari Kementrian Perindustrian Republik Indonesia, pada tahun 2009 ekspor keramik mencapai 234.717.570 US\$, tahun 2010 mencapai 316.266.324 US\$ dan tahun 2011 mencapai 356.972.301 US\$ (Kementrian Perindustrian Republik Indonesia, 2012).
Malang merupakan salah satu kota di Provinsi Jawa Timur yang memiliki potensi akan kerajinan keramik yang terpusat di Daerah Dinoyo. Kerajinan keramik Dinoyo mulai dirintis oleh perajin sejak tahun 1950. Sampai saat ini, jumlah perajin keramik Dinoyo telah mengalami peningkatan, dari awal mula berjumlah 50 hingga sekarang terdapat sekitar 300 perajin keramik yang aktif dalam pembuatan kerajinan keramik di Dinoyo.

Sebagai salah satu potensi wisata di Kota Malang, sarana dan prasarana yang berkaitan dengan kerajinan keramik Dinoyo haruslah dapat menarik para wisatawan yang datang ke Kota Malang. Wisata yang dimaksud yaitu dalam hal edukasi dan pemasaran kerajinan keramik Dinoyo. Sarana dan prasarana edukasi yang sudah ada, merupakan sarana yang tidak 
dirancang untuk wisatawan, sehingga persyaratan ruang yang kondusif untuk edukasi dan pemasaran belum terpenuhi.

Selain itu, pemerintah Kota Malang juga sedang gencar mempromosikan Kota Malang sebagai kota tujuan wisata yang mempunyai banyak potensi dan ciri khas tersendiri. Salah satunya dengan mengandalkan potensi dari kerajinan keramik Dinoyo yang telah ditetapkan sebagai salah satu tujuan wisata kerajinan keramik di Kota Malang. Hal tersebut juga dapat dilihat dari diselenggarakannya festival keramik tahunan di Kota Malang yang sudah dua kali terselenggara dan mendapatkan tanggapan yang cukup memuaskan. Pemerintah Kota Malang juga memiliki tujuan melestarikan kerajinan keramik Dinoyo ini agar tidak hilang begitu saja dengan lebih memperkenalkan kerajinan tersebut kepada publik.

Berdasarkan berbagai tinjauan di atas, kelengkapan sarana dan prasarana di Dinoyo sebagai salah satu tujuan wisata di Kota Malang, tentunya akan sangat membantu dalam mempromosikan kerajinan keramik Dinoyo serta peningkatan minat wisata di Kota Malang. Oleh karena itu dibutuhkan suatu wadah yang dapat menampung seluruh kegiatan edukasi dan pemasaran kerajinan keramik berupa Malang Ceramic Craft Center.

Bangunan Malang Ceramic Craft Center yang direncanakan menggunakan konsep Arsitektur Regionalisme dalam perancangannya. Regionalisme diharapkan dapat menghasilkan bangunan yang bersifat abadi, melebur atau menyatu antara yang lama dan yang baru, antara regional dan universal (Curtis, 1985). Penerapan konsep Arsitektur Regionalisme juga diharapkan dapat menghasilkan bangunan yang memunculkan citra budaya lokal Kota Malang dengan memasukkan unsur-unsur lokal ke dalam bangunan, terkait dengan kerajinan keramik yang merupakan kerajinan khas Kota Malang. Unsur lokal tersebut digabungkan dengan unsur modern sehingga bangunan memiliki kesesuaian antara arsitektur lokal dan perkembangan zaman.

\section{METODE}

Metode yang digunakan untuk mencapai tujuan dan sasaran perencanaan dan perancangan adalah metode pemrograman arsitektur yang terdiri dari gagasan awal, temuan dan penelusuran masalah, pencarian data, pengolahan data dan informasi, konsep perencanaan (building performance concept), konsep perancangan (programming and design) dan transformasi arsitektur.

Penelusuran masalah dimulai dengan melakukan survey langsung ke lokasi wisata kerajinan keramik Dinoyo. Permasalahan yang didapat adalah kurangnya sarana dan prasarana yang menunjang kegiatan wisata edukasi kerajinan keramik, padahal Dinoyo sudah ditetapkan sebagai salah satu objek wisata di Kota Malang.

Setelah permasalahan ditemukan, dilakukan analisis perencanaan (building concept) yaitu mengidentifikasi masalah yang ada berdasarkan konsep desain fasilitas wisata edukasi kerajinan keramik yang diselesaikan dengan penerapan Arsitektur Regionalisme. Arsitektur Regionalisme dipilih sebagai tema pendekatan dikarenakan keterkaitan dengan objek wisata edukasi yaitu kerajinan keramik yang merupakan salah satu kerajinan khas Kota Malang, sehingga nantinya diharapkan bangunan yang direncanakan akan lebih menonjolkan sisi budaya Kota Malang.

Arsitektur Regionalisme sebagai tema pendekatan dalam perancangan Malang Ceramic Craft Center juga sebagai batasan dalam menentukan material, struktur, olahan bentuk massa serta tampilan bangunan.

Analisis perancangan (building criteria) dilakukan dengan mengolah data yang telah terkumpul dan dikelompokkan berdasarkan pemrograman fungsional, performansi dan arsitektural.

1. Pemrograman fungsional bertujuan untuk mengidentifikasi penggunaan Malang Ceramic Craft Center, di antaranya pelaku kegiatan, jenis kegiatan, pola kegiatan, sifat kegiatan, sifat organisasi. 
2. Pemrograman menerjemahkan

performansi secara sistematik kebutuhan para pengguna Malang Ceramic Craft Center beserta fasilitasnya ke dalam persyaratan pemilihan tapak, persyaratan kebutuhan ruang, persyaratan besaran ruang dan program ruang.

3. Analisis arsitektural merupakan tahap penggabungan dari hasil identifikasi kedua analisa sebelumnya (fungsional dan performansi). Dalam proses ini akan menganalisa masalah massa, ruang, tampilan, pengolahan tapak, utilitas dan struktur bangunan yang menyatukan akan tuntutan kebutuhan pengguna dengan persyaratan yang ada.

Setelah dilakukan analisis pemrograman fungsional, pemrograman performansi dan arsitektural, langkah selanjutnya yaitu melakukan sintesis. Sintesis merupakan tahap penggabungan dari referensi dan hasil analisis fakta lapangan sehingga didapat kesimpulan untuk memperoleh konsep perancangan yang sesuai yang akan ditransformasikan ke bentuk fisik yang diinginkan, yaitu Malang Ceramic Craft Center dengan pendekatan Arsitektur Regionalisme di Kota Malang.

\section{ANALISIS}

\subsection{Analisis Peruangan}

1. Tujuan: Memperoleh jenis kebutuhan ruang.

2. Dasar pertimbangan: Pengelompokan kegiatan dan pelaku kegiatan.

3. Hasil analisa:

Konsep analisis pelaku kegiatan pada Malang Ceramic Craft Center adalah:

a. Pengunjung

b. Pengelola

Berikut total luasan ruang yang dibutuhkan berdasarkan kelompok kegiatan:
a. Kegiatan utama $2716 \mathrm{~m}^{2}$
b. Kegiatan pendukung $1566 \mathrm{~m}^{2}$
c. Kegiatan pengelola : $344 \mathrm{~m}^{2}$

d. Kegiatan servis

$$
3036 \mathrm{~m}^{2}
$$

\subsection{Analisis Pemilihan Lokasi}

1. Tujuan:

Mendapatkan lokasi yang sesuai dan mendukung sebagai area didirikannya bangunan.

2. Dasar pertimbangan:
a. Merupakan daerah kunjungan wisata
b. Dekat dengan lokasi pembuatan kerajinan keramik Dinoyo
c. Sesuai dengan peruntukan tata guna lahan dalam RTRW Kota Malang
d. Kemudahan dalam pencapaian

3. Hasil analisis:

Tapak terpilih yang akan dijadikan lokasi pembangunan Malang Ceramic Craft Center, yaitu di Jalan MT Haryono. Tapak berbatasan langsung dengan Jl. MT Haryono dan Universitas Brawijaya pada sisi Selatan, permukiman penduduk pada sisi Barat, Sungai Brantas pada sisi Utara dan Jl. Soekarno Hatta pada sisi Timur (lihat Gambar 1).

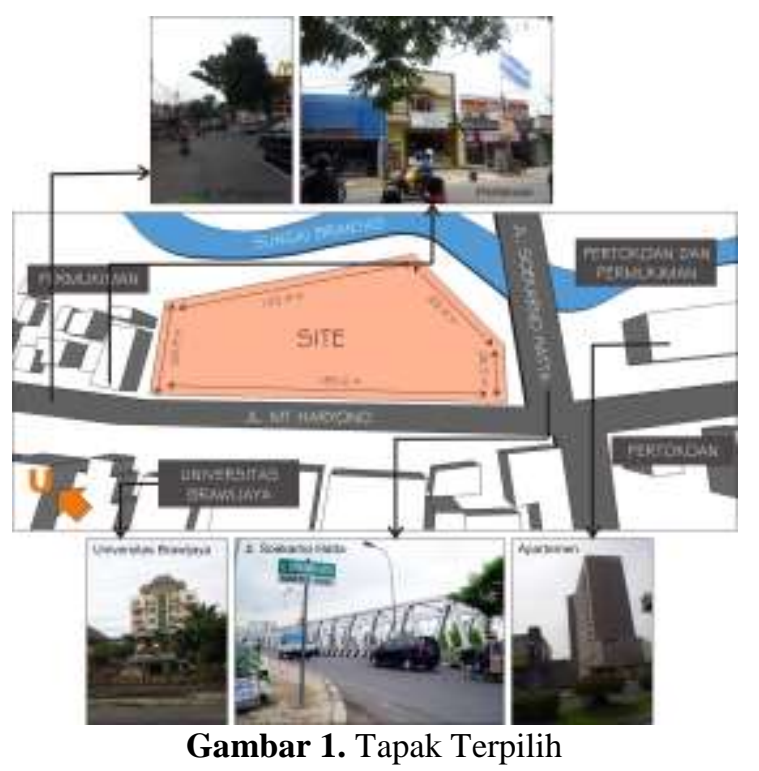

3.3 Analisis Pencapaian

1. Tujuan:

Menentukan main entrance dan side entrance.

2. Dasar pertimbangan:

Kondisi dan potensi jalan, sirkulasi yang jelas dan mudah dicapai serta keamanan dan kenyamanan sirkulasi. 
3. Hasil analisis:

Main entrance (ME) bagi pengunjung diletakkan pada sisi Selatan tapak yang berbatasan langsung dengan $\mathrm{Jl}$. MT Haryono. Untuk akses ke luar tapak menggunakan akses berbeda yaitu pada sisi Timur tapak yang berbatasan langsung dengan Jl. Soekarno Hatta. Pemisahan antara jalur masuk dan ke luar sebagai upaya untuk mengurangi kepadatan jalan dan mencegah terjadinya kemacetan.

Jalur ke luar masuk pengelola menggunakan side entrance (SE) yang terletak pada sisi bagian Barat tapak di Jl. MT Haryono. Pemisahan antara ME dan SE dengan pertimbangan mencegah terjadinya crossing kegiatan sirkulasi antara pengunjung dan pengelola (lihat Gambar 2).

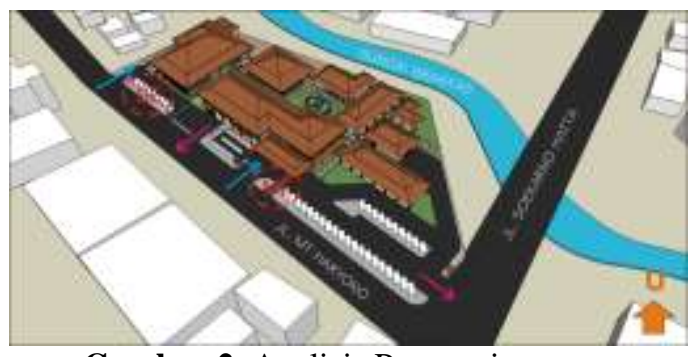

Gambar 2. Analisis Pencapaian

\subsection{Analisis Bentuk dan Tampilan Bangunan}

3.4.1 Analisis penentuan konsep Arsitektur Regionalisme

Penentuan konsep Arsitektur Regionalisme digunakan untuk menentukan aspek-aspek yang terkait dalam konsep Arsitektur Regionalisme yang akan digunakan sebagai pertimbangan dalam proses perencanaan dan perancangan desain bangunan Malang Ceramic Craft Center di Kota Malang.

Aspek-aspek yang terkait dalam Arsitektur Regionalisme dapat dilihat dari bagan berikut:

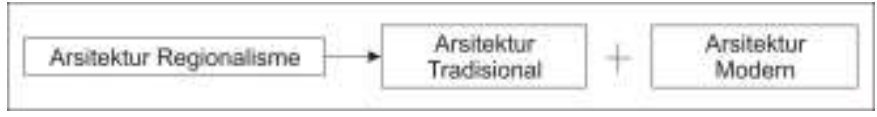

Bagan 1. Analisis Aspek-Aspek Arsitektur Regionalisme

Arsitektur Tradisional yang berlaku di Kota Malang adalah Arsitektur Jawa. Arsitektur Jawa berawal dari Arsitektur Vernakular yang terbentuk dari hasil penyesuaian terhadap iklim, kondisi sosial, budaya dan tradisi masyarakat Jawa.

Selain aspek arsitektural dan unsurunsur lokal yang terkait, karakter objek yang diwadahi juga memegang peranan dalam penentuan konsep Regionalisme pada bangunan Malang Ceramic Craft Center yang direncanakan. Penyesuaian dengan karakter objek yang diwadahi dapat menguatkan identitas Malang Ceramic Craft Center.

\subsubsection{Analisis bentuk bangunan}

Malang Ceramic Craft Center menggunakan pendekatan Arsitektur Regionalisme, sehingga bentuk massa bangunan menyesuaikan bangunan yang ada di sekitar tapak dan diharapkan dapat memunculkan citra budaya lokal Kota Malang. Bangunan yang terdapat di sekitar tapak sebagian besar menerapkan gaya Arsitektur Jawa.

Bentuk dasar massa bangunan yang direncanakan diutamakan berbentuk persegi panjang, dikarenakan mengikuti bentuk dasar denah pada bangunan Arsitektur Jawa. Selain itu, dengan bentuk massa yang persegi, dapat lebih memudahkan penataan ruang dan sirkulasi bangunan serta mengoptimalkan fungsi ruang.

Tata massa bangunan pada Malang Ceramic Craft Center juga tidak lepas dari konsep Arsitektur Regionalisme. Pada bangunan Jawa, terdapat suatu urutan tatanan peletakan bangunan secara linier dari bangunan luar yang bersifat publik dan semakin ke dalam bersifat semakin privat.

Pada bangunan Malang Ceramic Craft Center yang menerapkan konsep Arsitektur Regionalisme bangunan Jawa, dapat dilihat dari peletakan bangunan 
pada bagian depan yang bersifat publik yaitu bangunan penerima dan bangunan pemasaran, kemudian peletakan bangunan yang bersifat semi publik setelah bangunan publik yaitu bangunan utama yang mewadahi kegiatan edukasi baik aktif maupun pasif, dan yang terakhir peletakan bangunan yang bersifat privat yaitu bangunan pengelola dan bangunan pendukung yang diperuntukkan bagi perajin (lihat Gambar 3).

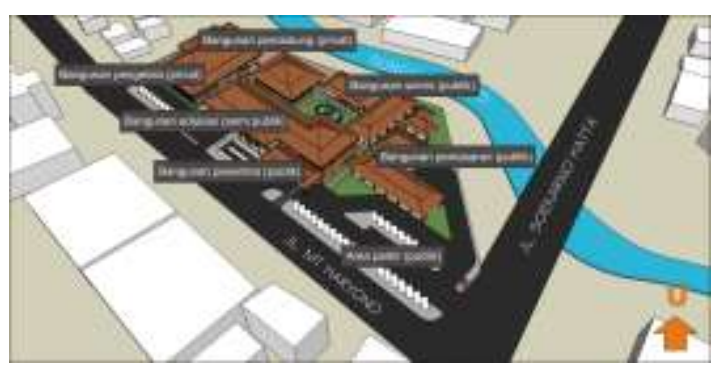

Gambar 3. Analisis Tata Massa Bangunan

\subsubsection{Analisis tampilan bangunan}

Arsitektur Regionalisme pada tampilan bangunan Malang Ceramic Craft Center meliputi Arsitektur Jawa dan disesuaikan dengan arsitektur kawasan sekitar serta terkait dengan objek material edukasi.

Bentuk atap yang digunakan yaitu atap joglo. Untuk material atap menggunakan genteng tanah liat. Penggunaan warna dominan coklat dan krem menyesuaikan warna bangunan sekitar (lihat Gambar 4).

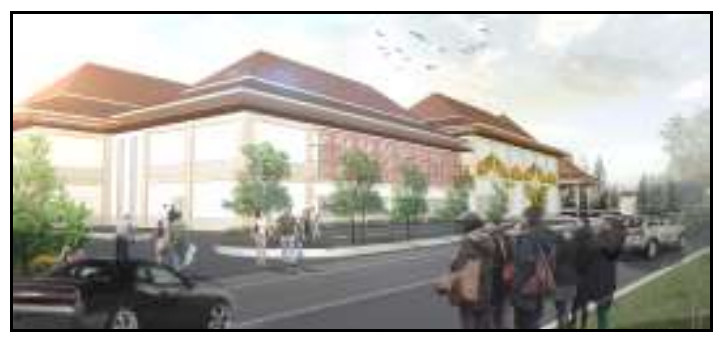

Gambar 4. Analisis Tampilan Bangunan

Penggunaan ornamen dengan corak yang biasa digunakan pada kerajinan keramik khas Kota Malang yang diaplikasikan ke dalam bangunan dapat mencerminkan identitas bangunan sebagai pusat kerajinan keramik dan juga memberikan gambaran visual kepada pengunjung terkait dengan kerajinan keramik yang ada di Kota Malang (lihat Gambar 5).

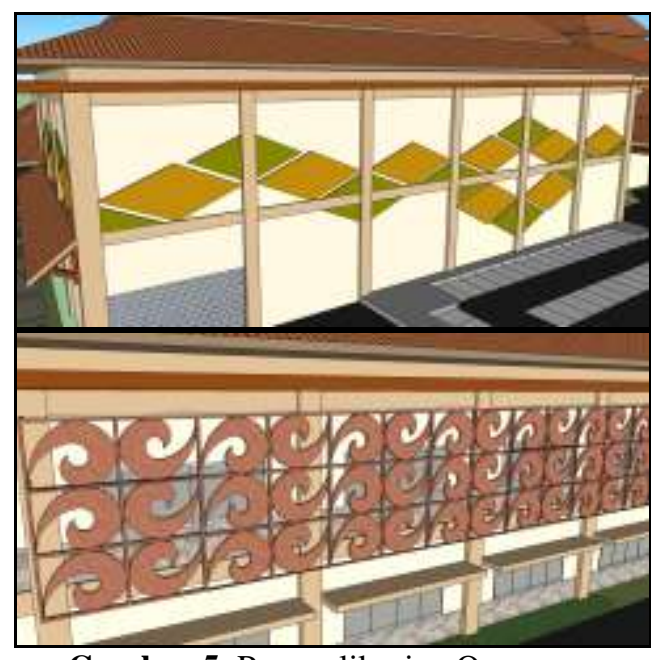

Gambar 5. Pengaplikasian Ornamen Kerajinan Keramik pada Bangunan

\subsection{Analisis Lansekap Kawasan}

Konsep lansekap kawasan pada Malang Ceramic Craft Center tidak lepas dari konsep Arsitektur Regionalisme, yaitu terdapat halaman depan dan halaman belakang pada kawasan yang ditanami pohon pelindung dan penanaman vegetasi secara simetris dan seimbang pada kawasan.

\section{KESIMPULAN (KONSEP DESAIN)}

Dari hasil analisa serta hasil korelasi dari beberapa data di atas, maka diperoleh hasil berupa desain Malang Ceramic Craft Center sebagai berikut.

Lokasi

: Jl. MT Haryono,

Luas Lahan $\quad: 10212 \mathrm{~m}^{2}$

Luas Bangunan : $7662 \mathrm{~m}^{2}$

Jumlah Lantai : 2 lantai

Daya Tampung : 300 orang

Pada bangunan Malang Ceramic Craft

Center ini, konsep Arsitektur Regionalisme diterapkan dengan penggunaan atap khas Jawa yaitu joglo (lihat Gambar 4), penggunaan warna dominan krem sebagai penyesuaian dengan bangunan sekitar, pola tatanan massa sesuai dengan pola tatanan massa bangunan Jawa (lihat Gambar 3), pengaplikasian ornamen kerajinan keramik pada bangunan (lihat Gambar 5), 
penggunaan material lokal pada bangunan seperti batu bata dan batu alam (lihat Gambar 6), penggunaan sculpture sebagai simbol objek material bangunan (lihat Gambar 7) serta pengunaan struktur modern dengan tetap menciptakan suasana lokal.

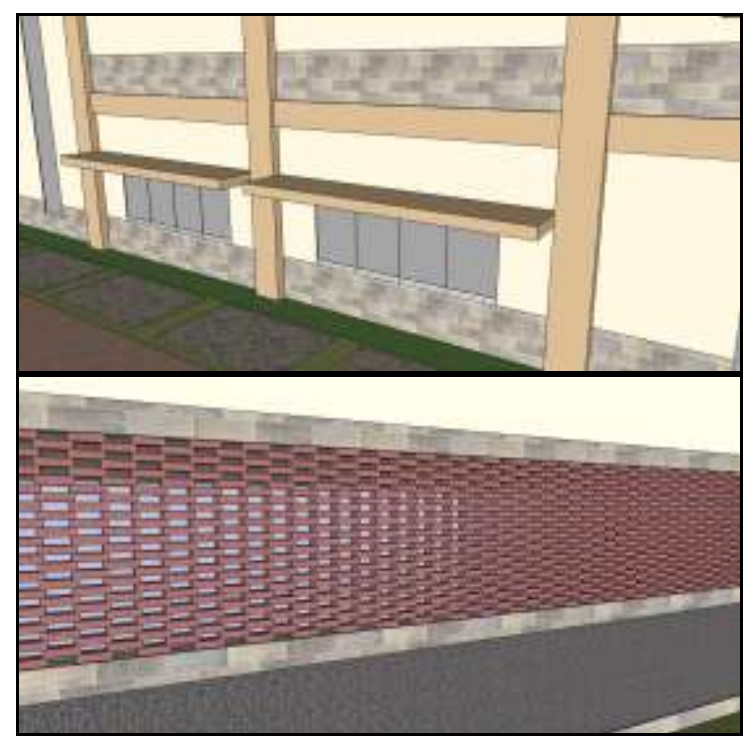

Gambar 6. Penggunaan Batu Alam dan Batu Bata pada Bangunan

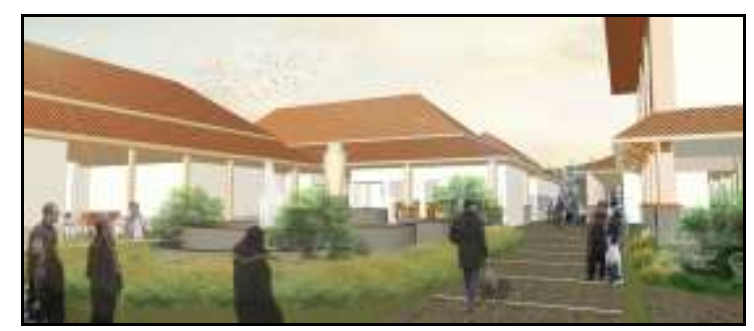

Gambar 7. Sclupture pada Open Space

\section{REFERENSI}

Curtis, William, 1985. Regionalism in Architecture. Singapura. Concept Media. Kementrian Perindustrian RI. 2012. "Pemantauan Ekspor Kelompok Hasil Industri Keramik, Marmer dan Kaca". Surakarta: http://kemenperin.go.id. 